\title{
Crystal Engineering: A Brief for the Beginners
}

\section{Partha Pratim Bag ${ }^{1 *}$ and Sumit Popat Mane ${ }^{2}$}

${ }^{1}$ Department of Chemistry, SRM University Sikkim, Sikkim-737102 India

${ }^{2}$ Bhagalpur College of Engineering, Sabour, Bhagalpur, Bihar-813210, India

*Corresponding Author: Partha Pratim Bag, Department of Chemistry, SRM

University Sikkim, Sikkim, India. E-mail: parthap.bag82@yahoo.com
Received: January 06, 2021

Published: Janaury 28, 2021

(C) All rights are reserved by Partha Pratim

Bag and Sumit Popat Mane.

\begin{abstract}
Crystals are formed by aggregation of molecules in solution. This phenomenon encourages several questions. Among them few are, how do these aggregations happen to form crystals? Why do same molecules adopt more than one crystal structure? Why does solvent occupy some crystal structures? How does crystal structure can be designed with a specified coordination of molecules and/ or ions with a specified property? What are the relationships between crystal structures and properties, for molecular crystals? At present several queries are being resolved by the crystal engineering community; a larger community constructed by organic, inorganic and physical chemists, crystallographers and solid-state scientists. This article provides brief idea to provide a basic introduction to crystal engineering and this fascinating and important subject that has moved from the fringes into the mainstream of chemistry.
\end{abstract}

Keywords: Crystal Engineering; Internmolecular Interaction; Synthetic Strategy; Supramolecule; Type of Solid

\section{Introduction}

What is crystal engineering?

The modern definition according to Gautam Desiraju, it is "the understanding of intermolecular interactions in the context of crystal packing and the utilization of such understanding in the design of new solids with desired physical and chemical properties [1]. So it offers good opportunity of the design of molecular crystals for a wide variety of physical and chemical purposes. Crystal engineering is quite resembling with organic chemistry on the basis of two components, analysis and synthesis. For designing a crystal and predict the structure experimentation and computation are of equally important [2]. Because with the help of experiment, structural information of supramolecular architecture could be obtained by further application of single crystal X-ray diffraction and computational approach could be helpful to enumerate the interactions for crystal packing in terms of thermodynamically stable product.

Formation of crystal is governed by recognition processes in supramolecular aggregation. Principally it is classified into two main categories; molecular recognition in solution is denoted as supramolecular chemistry, and periodic self-assembly in the solid state as crystal engineering (Figure 1) [3]. At the supramolecular level, molecular recognition is complementarity; even the functional groups of for same molecules are interacting in different way. Hydrogen bonds are formed when an electropositive hydrogen bond donor approaches an electronegative acceptor $\left(\mathrm{D}^{\delta-}---\mathrm{H}^{\delta+} \cdots \mathrm{A}^{\delta-}\right)$, cation $\cdots$ anion electrostatic interaction in salts and metal complexes $\left(\mathrm{M}^{+} \mathrm{X}^{-}\right)$, and bumps in one part of the molecule fit into hollows of another portion (hydrophobic interactions), and so on. 
Using the Crystal Engineering approach several types of solids are reported so far, such as co-crystals, polymorphs, individual API, Co-crystal polymorphs, metal-organic frameworks (MOFs) $[4,5]$ etc. The packing of all the solids can be analysed by supramolecular synthons.

The aim of this article is to provide a brief idea of basic introduction to this fascinating and important subject that has moved from the fringes into the mainstream of chemistry [6]. This article is mainly helpful to the new researchers who are interested to work in this field.

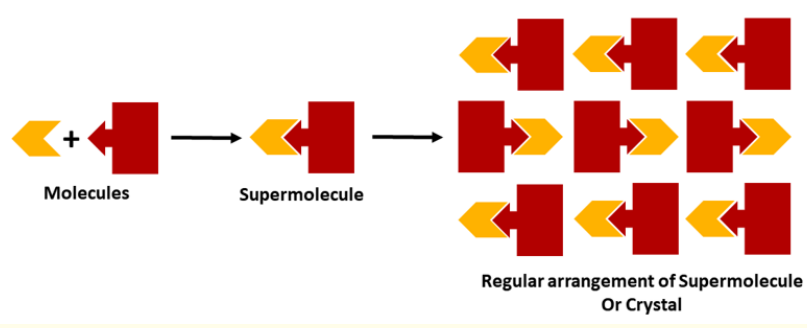

Figure 1: Molecular recognition of molecules to give supermolecule and periodic arrangement of supermolecules in a crystal lattice. Note the complementary shape and bonding feature of interacting molecules [3].

\section{Intermolecular interactions}

The analytical component of crystal engineering consists of studies of the various intermolecular interactions that are responsible for crystal assembly and of the systematic exploration of families of crystal structures that are based on particular interactions of choice.

The research on crystal engineering has been expanded by extensive interest in the nature of intermolecular interactions which are used in the formation of solid-state structures. Modern crystal engineering originated from the arrangement of molecules in the solid-state and now the subject continues to be motivated by the understanding of intermolecular interactions and their use in trying to control solid-state structures. Among several types of intermolecular interactions hydrogen bonds and coordination bonds widely studied. Well known strong hydrogen bonds are $\mathrm{N}-\mathrm{H} \cdots \mathrm{O}$ and
$\mathrm{O}-\mathrm{H} \cdots \mathrm{O}$ and are now routinely used for crystal architecture. Weak hydrogen bonds such as $\mathrm{C}-\mathrm{H} \cdots \mathrm{O}$ bonds in crystal structure design is still in its infancy but the early results hold much promise for the future [7]. Another type of bond $\mathrm{C}-\mathrm{H} \cdots \pi$ interaction is surely of the hydrogen bond type if the donor group is sufficiently acidic [8]. In the same way, $\mathrm{C}-\mathrm{H} \cdots \mathrm{X}$ (X is halogen) hydrogen bond are significant $[9,10]$.

The energy of different intermolecular interactions is given in table 1.

\begin{tabular}{|c|c|c|}
\hline Interaction type & $\begin{array}{c}\text { Energy (kcal } \\
\text { mol }^{-1} \text { ) }\end{array}$ & Examples \\
\hline Very strong $\mathrm{H}$ bonds & $15-40$ & $\begin{array}{c}\mathrm{O}---\mathrm{H} \cdots \mathrm{O}^{-}, \mathrm{F}---\mathrm{H} \cdots \\
\mathrm{F}^{-}\end{array}$ \\
\hline $\begin{array}{l}\text { Strong hydrogen } \\
\text { bonds }\end{array}$ & $5-15$ & $\begin{array}{c}\mathrm{O}---\mathrm{H} \cdots \mathrm{O}^{-}, \mathrm{N}---\mathrm{H} \cdots \\
\mathrm{O}^{-}\end{array}$ \\
\hline $\begin{array}{l}\text { Weak hydrogen } \\
\text { bonds }\end{array}$ & $1-4$ & $\begin{array}{c}\mathrm{C}---\mathrm{H} \cdots \mathrm{O}^{-}, \mathrm{O}--\mathrm{H} \cdots \\
\pi\end{array}$ \\
\hline Coordinative bonds & $20-45$ & M---N, M---O \\
\hline $\begin{array}{l}\text { van der Waals } \\
\text { interactions }\end{array}$ & $0.5-2$ & $\begin{array}{c}\mathrm{CH}_{3} \cdots \mathrm{CH}_{3} \\
\mathrm{CH}_{3} \cdots \mathrm{Ph}\end{array}$ \\
\hline $\begin{array}{l}\text { Heteroatom } \\
\text { interactions }\end{array}$ & $1-2$ & $\mathrm{~N} \cdots \mathrm{Cl}, \mathrm{I} \cdots \mathrm{I}, \mathrm{Br} \cdots \mathrm{Br}$ \\
\hline$\pi$-stacking & $2-10$ & $\begin{array}{c}\text { Ph‥Ph, } \\
\text { nucleobases }\end{array}$ \\
\hline
\end{tabular}

Table 1: Strength scale of different intermolecular interactions and hydrogen bonds [3].

\section{Strategy of synthesis}

The best synthetic strategy is the combination of methodology with imagination and perception. There are so many reports seen that describe the use of hydrogen bonded supramolecular synthons as a primary tool for the crystal engineering [11-18]. By using bis-isophthalic acid derivatives as building blocks, some of the supramolecular links were replaced in the parent trimesic acid network with stable intramolecular links [19]. When trimesic acid linked with 4,4'-bipyridine reveals an expanded hexagonal 2D network [20]. An inventive strategy was used to form a square hydrogen bonded network structure for 4,4'-sulfonyldiphenol [21]. This is doubly interpenetrated corrugated two-dimensional structure, contains two hydrogen bond donors and acceptors. Another report on perylene was co-crystallized with electron-deficient species, 
tetracyanohydroquinone, formed hydrogen bonded network by optimizing $\pi \cdots \pi$ interactions [22]. Weak $\pi \cdots \pi$ interactions are another type of dominant interaction can control 3D crystal structure.

For supramolecular synthesis, knowledge of both molecular and supramolecular levels is necessary and increasing complexity at the molecular level can bring with it a high degree of supramolecular specificity. In this context, crystal engineering might not be relaxed as like synthetic chemistry to prepare target-molecule. Universally, chemist sees a telescoping of the organo-physical, synthetic and application-oriented branches of crystal engineering in a manner that was unknown and unnecessary in the slower paced times that witnessed the growth of molecular organic chemistry [23].

\section{Types of solids}

Continuous development has meant that there is a considerable encouragement to design solids with very specific physical or chemical properties. Functionalization or various type of solid indicate that investigation of different form will dominate research efforts in the near future and already there are many reports that emphasize the idea of 'solids with a purpose' [23]. A major type solids with nonlinear optical (NLO) properties such as second harmonic generation (SHG). Perhydrotriphenylene is known to form channel-type inclusion compounds and many long polarizable molecules have their dipoles parallel rather than antiparallel in the channels of the host material leading to bulk SHG [24].

Crystal engineering also cover fullerene chemistry domain which is an interesting topochemical metathesis reaction; the bisadduct of anthracene and $\mathrm{C}_{60}$ has been obtained from the monoadduct. Schmidt imagined this combination of crystal engineering with solid state topochemical control and opens routes to highly specific fullerenes and, in general, to 'programmed' molecular synthesis [25].

Crystal engineering highly connected with pharmaceutical solids [26] such as co-crystal, polymorph, solvate etc.

\section{Co-crystal}

The definition of co-crystal has been a topic of debate in recent years. G. R. Desiraju defined it as "multi-component crystals with clearly defined intermolecular interactions, i.e., non-covalent, in- teractions between the component molecules, be termed "molecular complex" [27]. J. D. Dunitz [28] also agree with that.

Bond suggested that "co-crystals" are composed of multi-component, stoichiometric and neutral molecular species, that themselves each exists as a solid under ambient conditions [29].

Michael J. Zaworotko states Pharmaceutical co-crystals, as "cocrystals that are formed between a molecular or ionic API and a co-crystal former that is a solid under ambient conditions" [30].

\section{Polymorph}

It was first recognized by Mitscherlich [31]. Polymorphs are different crystalline forms of the same pure substance in which molecules have different arrangements and/or different molecular conformation.

\section{Solvate/hydrate}

If solvent molecule come into the crystal structure as one component of crystal, then the solid is called solvate [32]. When water replaced the solvent molecule in a crystal structure, is called hydrate.

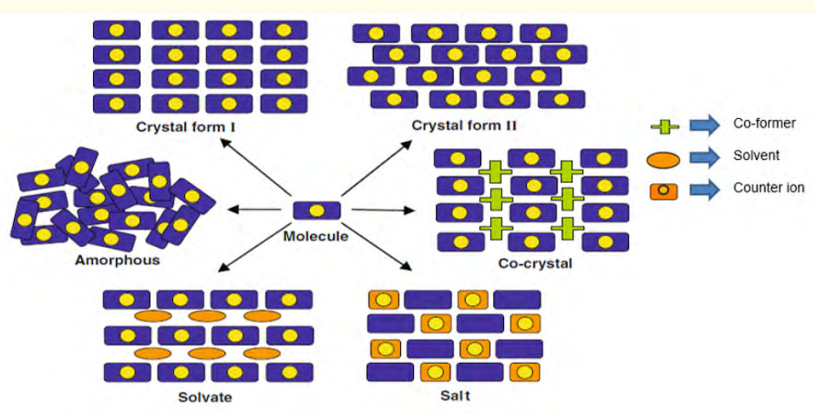

Figure 2: Structural relationship between "true" polymorphs, solvates, co-crystals, salts and the amorphous phase [32].

\section{Conclusions}

Behind molecular structure, there is always a nice chemistry which is mostly unknown to most of the people. As for example why is a particular organic molecule consisting a particular type of packing arrangement? There are a lot of factors works such as hydrogen bond (both strong and weak), electrostatic interactions, 
van der Walls force, $\pi \cdots \pi$ interactions, solvent effect, temperature etc. So organic chemistry deals with molecule-based but crystal engineering is supermolecule-based. It is clear that communications and networks between molecular and supramolecular structure lie at the core of the subject. Such transforms are the most useful of supramolecular synthons to identify the particular form. To predict the crystal structures from molecular structures with or without partial crystallographic information, computational studies are conveniently carried out with programs such as Cerius [33] from Molecular Simulations; In the crystal engineering viewpoint these approaches are of significance for many materials where structure cannot be obtained from single crystals for X-ray diffraction studies [34].

The ultimate goal of this article is to provide a knowledge about different types of interactions in crystalline solids and how they work. It is expected from the analysis and synthesis of crystalline supermolecules to lead to new families of designer solids with truly tuneable properties. We might surely expect progress in these related areas in the near future.

\section{Bibliography}

1. G R Desiraju. Crystal Engineering. The Design of Organic Solids, Elsevier, Amsterdam (1989).

2. GR Desiraju. "Crystal engineering: solid state supramolecular synthesis". Current Opinion in Solid State and Materials Science 2.4 (1997): 451-454.

3. A Nangia. "Supramolecular chemistry and crystal engineering". Journal of Chemical Sciences 122.3 (2010): 295.

4. P P Bag and P Sahoo. "Designing Metal-Organic Frameworks Based Photocatalyst for Specific Photocatalytic Reactions: A Crystal Engineering Approach". In: Rajendran S., Naushad M., Ponce L., Lichtfouse E. (eds) Green Photocatalysts for Energy and Environmental Process. Environmental Chemistry for a Sustainable World 36 (2020).

5. P P Bag., et al. "Synthesis of Metal-Organic Frameworks (MOFs) and Their Applications to Biology, Catalysis and Electrochemical Charge Storage: A Mini Review". Engineered Science (2020).

6. G R Desiraju., et al. Crystal Engineering A Textbook (2011).
7. G R Desiraju. "The $\mathrm{C}-\mathrm{H} \cdots \mathrm{O}$ Hydrogen Bond: Structural Implications and Supramolecular Design". Accounts of Chemical Research 29 (1996): 441-449.

8. A S Batsanov., et al. Chemical Communications (1996): 1791.

9. J A K Howard., et al. Tetrahedron 62 (1996): 12613.

10. J D Dunitz and R Taylor. Chemistry-A European Journal 3 (1997): 69.

11. S Ghosh., et al. Crystal Growth and Design 11(2011): 3489.

12. P P Bag., et al. CrystEngComm 16 (2014): 7393.

13. P P Bag., et al. CrystEngComm 16 (2014): 4706.

14. P P Bag and C M Reddy. Proceedings of the National Academy of Sciences, India. Section A: Physical Science 84.2 (2014): 235.

15. T Chatterjee., et al. RSC Advances 3.46 (2013): 24021.

16. T Chatterjee., et al. Physical Chemistry Chemical Physics 17(2015): 20515.

17. C V K Sharma., et al. Chemical Communications (1996): 2655.

18. M Yaghi., et al. Journal of the American Chemical Society 116 (1996): 9096.

19. A Zafar., et al. Tetrahedron Letter 37 (1996): 2327.

20. C V K Sharma and M J Zaworotko. Chemical Communications (1996): 2655.

21. C Glidewell and G Ferguson. Acta Crystallogr C, 52 (1996): 2526.

22. H Bock., et al. Angewandte Chemie International Edition 35 (1996): 2244.

23. G R Desiraju. Current Opinion in Solid State \& Materials Science 2 (1997): 451.

24. R Hoss., et al. Angewandte Chemie International Edition 35 (1996): 1664.

25. B Krautler., et al. Angewandte Chemie International Edition 35 (1996): 1204. 
26. P P Bag. Acta Scientific Pharmaceutical Sciences 4.3 (2020): 1.

27. G R Desiraju. CrystEngComm 5 (2003): 466.

28. J D Dunitz. CrystEngComm 5 (2003): 506.

29. A D Bond. CrystEngComm 9 (2007): 833.

30. P Vishweshwar., et al. Journal of Pharmaceutical Sciences 95 (2006): 3.

31. E Mitscherlich. Annales de chimie et de physique 19 (1821): 414.

32. D Braga., et al. Structure and Bonding 132 (2009): 25.

33. T Steiner. Crystal Review 6 (1996): 1.

34. P P Bag. Engineered Science (2021). DOI:10.30919/es8d1004

\section{Assets from publication with us}

- Prompt Acknowledgement after receiving the article

- Thorough Double blinded peer review

- Rapid Publication

- Issue of Publication Certificate

- High visibility of your Published work

Website: www.actascientific.com/

Submit Article: www.actascientific.com/submission.php

Email us: editor@actascientific.com

Contact us: +919182824667 